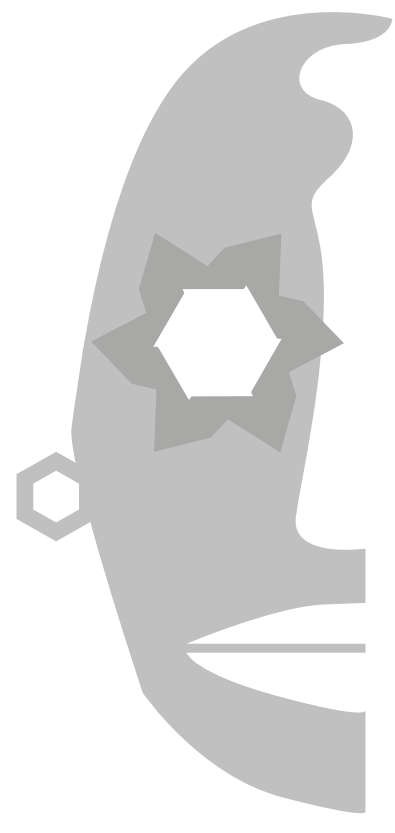

Sergio Coto-Rivel

Universidad de Nantes

Francia

\section{Enrique Gómez Carrillo, un viaje a las trincheras (1914-1915)}

\section{Resumen}

El escritor guatemalteco Enrique Gómez Carrillo (1837-1921), viajero y diplomático reconocido, produjo una importante obra que reúne crónicas periodísticas sobre la vida parisina, el mundo intelectual de la Belle Époque y sus viajes en Oriente. Sin embargo, encontramos también una importante producción de crónicas de guerra publicadas en español y en francés desde el inicio de la Primera Guerra Mundial. En efecto, el escritor visita el frente de batalla junto con un grupo de periodistas provenientes de países neutros al conflicto, su objetivo es el de informar en periódicos españoles sobre las atrocidades cometidas, la devastación y los testimonios de las víctimas desde el inicio de la guerra. En el presente artículo nos proponemos analizar las estrategias narrativas puestas en práctica por el cronista con el fin de estudiar de qué manera aporta una perspectiva particular y personal del conflicto armado que abrasa el continente europeo. De esta forma, nos interesamos por las estrategias literarias propias del relato de viajes que se encuentran presentes en las crónicas y que llevan la narración más allá del estatuto de reportaje para dar una visión íntima del desastre y el horror.

Palabras clave: Primera Guerra Mundial, crónicas de guerra, literatura guatemalteca, relato de viaje

\footnotetext{
Abstract

The Guatemalan writer Enrique Gómez Carrillo (1837-1921), a renowned traveler and diplomat, produced an important body of work, which brought together news chronicles about the Parisian life, the intellectual world of the Belle Époque and his journeys to the East. However, we also encounter an important production of war chronicles published in Spanish and French from the beginning of World War I. As a matter of fact, the writer went to the war front along with
} 
a group of journalists from different neutral countries. His goal was to inform of the atrocities, the devastation and to report war victims' testimonies. In this article, we propose to analyze the narrative strategies that were used by the columnist, so as to study in what way it brought a particular and personal perspective on the armed conflict that was setting Europe ablaze. We will thus examine the strategies specific to the travel stories that were used in the chronicles and that carried his narration beyond the status of reporting in order to give an intimate vision of the disaster and the horror.

Keywords: World War I, war chronicles, Guatemalan literature, travel stories

\section{Introducción}

Al tratar la temática del viaje en la literatura latinoamericana de finales del siglo XIX e inicios del XX, es inevitable interesarse de manera particular en la obra del escritor guatemalteco Enrique Gómez Carrillo (1873-1927). Su prosa modernista, rica en descripciones y referencias abundantes, así como su estilo ameno y desenvuelto, le valieron el reconocimiento más allá del mundo hispánico. Todo esto gracias a una importante cantidad de crónicas publicadas en la prensa española y latinoamericana que eran luego recopiladas rápidamente en forma de libros; además, de las traducciones de sus obras en francés o inglés. La observación de las costumbres y los detalles cotidianos, así como los distintos caracteres de pueblos distantes resaltan en dichas crónicas. Sus relatos de viaje son presentados como una serie de "sensaciones" en las que se reconoce, según el autor, el alma del artista y el placer del viaje mismo. Sin embargo, en el presente artículo nos interesaremos en una variante dentro del trabajo de cronista de Gómez Carrillo relativa a la época en la que se vio inmerso no en la vida mundana parisina o en los viajes en Oriente, sino frente a los desastres de la batalla ocasionados por la Gran Guerra.

Nos interesa saber de qué manera la confrontación con el paisaje de ruinas y las características de la guerra moderna son desarrolladas por el autor para informar al público hispanohablante ¿Podemos hablar de crónicas de un corresponsal de guerra o de "sensaciones" a la manera del viaje modernista hacia la crudeza de la batalla? Esta es la pregunta que guiará, en un primer momento, nuestra reflexión.

\section{Excursión al campo de batalla}

Tan solo tres meses después del inicio del conflicto bélico en agosto de 1914, el ministro francés de Asuntos Extranjeros, Théophile Delcassé, invitó a un grupo de periodistas de países que se habían declarado neutrales a visitar el frente de batalla. Dicha invitación tenía como objetivo informar a la población en los principales medios de estos países desde un punto de vista favorable a los aliados y 
así luchar contra la influencia germánica ${ }^{1}$. Para el caso de España, es Gómez Carrillo quien recibe la invitación oficial como corresponsal del periódico madrileño El Liberal ${ }^{2}$. Este mismo periódico publica el telegrama urgente del ministro, así como la respuesta inmediata del escritor en la cual acepta agradecido el llamado a una "excursión organizada en la región de la guerra"3. Gómez Carrillo hace pocas referencias a la composición del grupo de periodistas que lo acompañaron ${ }^{4}$, sin embargo, podemos encontrar la lista de los participantes en uno de los artículos publicados por el periodista sueco Sjoestedt (1915) quien fue invitado igualmente para representar a su país 5 :

$\mathrm{Au}$ Ministère des Affaires étrangères je fus présenté à mes compagnons de route: MM. Carillo, du Libéral de Madrid; Cohen, du Télégraaf d'Amsterdam; Dr. Eide, pour la Norvège; F. de Jessen, correspondant de guerre connu, pour le Danemark; Sarti, représentant de La Tribuna, de Rome; Simms, pour United Press of América; Wagnère [sic.], directeur du journal de Genève. Nous sommes accompagnés de trois aimables cicérones : le capitaine V., les lieutenants D. et G., appartenant tous à l'arme [sic.] de la cavalerie. Pendant deux ou trois semaines nous voyagerons parallèlement avec les douze attachés militaires des pays neutres et la mission militaire des Etats-Unis. (p. 5)

El Liberal aprovecha el anuncio de la partida de uno de sus redactores hacia el campo de batalla para comunicar a sus lectores la próxima publicación de crónicas de un testigo presencial, dando así a entender la fiabilidad de los hechos que serán narrados por Gómez Carrillo: "Hora era ya de que la Prensa española pudiese dar noticias ciertas de la gran catástrofe europea, y hora es de que un testigo presencial nos cuente lo que allí pasa" (El Liberal, 10 de noviembre de 1914). De esta manera, las crónicas escritas desde los campos arrasados por las batallas en Francia son publicadas en el periódico español, así como en La Nación de Argentina. Posteriormente, tan solo unos meses después, Gómez Carrillo realiza una recopilación de estos textos para presentarlos en forma de libro bajo el título Campos de batalla y campos de ruina ${ }^{6}$, el cual aparecerá traducido al francés el

1 Podemos ver estas intenciones en el libro publicado por uno de los periodistas presentes, Sjoestedt (1915), quien explica en la introducción a la traducción de sus crónicas al francés que "Elles n'ont d'autre intérêt que de montrer au public français comment l'armée française est appréciée dans les pays neutres, et comment les amis de la France s’y efforcent de présenter les événements sous leur vrai jour” (párr. 1).

2 Para ampliar las perspectivas sobre las lecturas, crónicas y representaciones literarias de la Primera Guerra Mundial en autores latinoamericanos véase: Siskind, M., 2016.

3 La nota fue publicada en El Liberal el día martes 10 de noviembre de 1914 bajo el título "Gómez Carrillo a la guerra".

4 En la crónica El campo de batalla de Verdún (1922) dice Gómez Carrillo: "El capitán Valotte nos presenta, no por nuestros nombres, sino por los países que representamos: — Suiza, Holanda, Dinamarca, Noruega, Estados Unidos, Italia, España...” (p.127)

5 Los artículos de Sjoestedt (1915) aparecieron en los periódicos suecos: el Stockholms Dagblad, el Sydsvenska Dagbladet y en el Handels-Tidning.

6 Texto publicado en 1915, mas en este artículo se utiliza la edición de 1922. 
mismo año como Parmi les ruines, de la Marne au Grand Couronné y al inglés como Among the ruins. La rápida difusión de las crónicas de guerra en forma de libro, así como sus traducciones, nos da una idea del alcance obtenido por el autor en esta campaña de prestigio del ejército francés, una forma más de difundir las ideas propagandísticas de apoyo a la causa de los aliados?

Campos de batalla (1922) recoge en total 25 crónicas que dan cuenta, de forma aproximada, del recorrido realizado por el grupo de periodistas guiados por miembros del Estado Mayor francés a partir de la segunda quincena de noviembre 1914. "La excursión", como es llamada en el telegrama del ministro, parte de París hacia Fontainebleau con el objetivo de visitar primeramente los pueblos arrasados en el departamento de la Seine hacia la ciudad de Meaux. Este primer recorrido da cuenta de los ataques alemanes durante la primera batalla del Mar$\mathrm{ne}^{8}$. Posteriormente el grupo se desplaza a Reims, Verdún, Nancy, Metz y Luneville, el libro concluye con una crónica en la que el autor analiza la figura del soldado francés y su coraje.

\section{De la impresión del viaje al viaje como testimonio}

A partir de lo anterior podemos entonces notar el contexto altamente politizado en el cual las crónicas son presentadas. Primeramente, como una invitación institucional del Estado francés y, posteriormente, como una manera de informar a los países de habla hispana sobre el desarrollo de las primeras batallas en el territorio francés. Estos elementos toman además un cariz distinto al otorgar el estatuto de testigo presencial, es decir, de aquel que puede contar su propia experiencia y que por esta razón resulta digno de confianza. No debemos olvidar de igual forma, que es precisamente a partir de la palabra de los testigos de la Gran Guerra - particularmente aquellos que vivieron en carne propia la experiencia de las trincheras - que se empieza a conformar un discurso que otorga un valor preponderante al testimonio. Son estos relatos de guerra que fueron posteriormente estudiados con detalle para reconstruir elementos esenciales de los discursos históricos del siglo $\mathrm{xx}$, relacionados especialmente con las guerras mundiales 9 .

Es evidente que el caso de las crónicas no se presenta directamente como la voz del combatiente - puesta en valor posteriormente no solamente desde los textos literarios, sino también en los relatos testimoniales recogidos por Jean Norton

7 De la misma forma en que los textos de Gómez Carrillo alcanzan una importante difusión, podemos notar la rápida publicación de las crónicas del periodista sueco Sjoestedt, antes citado, y también las del director del Journal de Genève, Georges Wagnière, en 1915: Près de la guerre: en Suisse, en France, en Angleterre, sur le front.

8 Batalla que se desarrolla entre el 5 y el 12 de septiembre de 1914.

9 A este respecto es necesario citar el trabajo de Wieviorka, A., 1998. 
$\mathrm{Cru}^{10}$ - , pero esta es buscada constantemente y consignada en diálogos o largos relatos acentuando la idea de veracidad textual. Así entonces, Gómez Carrillo introduce la voz de los testigos de forma constante en la narración, lo que evidencia, en la mayoría de los textos de Campos de batalla (1922), una suerte de labor de entrevistador que permite a los habitantes de los pueblos arrasados por los bombardeos y atemorizados por la ocupación del territorio expresar no solo sus aflicciones, sino también su orgullo.

Los textos de Campos de batalla (1922) de Gómez Carrillo, así como los libros posteriores que recopilan su experiencia de reportero bélico ${ }^{11}$, constituyen un género híbrido que se encuentra en el cruce de la crónica modernista, los relatos de viaje y la crónica de guerra. Ya de por sí, el mismo género de la crónica desarrollado por el autor en relación con la vida bohemia de París, por ejemplo, implica una importante heterogeneidad en sus formas y temas, en particular en su relación muchas veces contradictoria con los elementos periodísticos que la componen. A este respecto González (1983) señala:

Generalizando, pues, podríamos afirmar que, desde sus inicios, la crónica se sitúa en la encrucijada de tres instituciones textuales desarrolladas en el siglo xIx: la filología, la literatura y el periodismo. Como género periodístico, la crónica está sujeta a exigencias de actualidad, de novedad y a lo que podríamos llamar "leyes de oferta y demanda", ya que desde el punto de vista del periodismo, la crónica es una mercancía. Por otra parte, es este valor de mercancía el que determina la relación de la crónica con el binomio literatura/filología, pues, para ser más específicos, la crónica es una mercancía de lujo. (p.75)

Es posible identificar estos elementos híbridos en la obra de Gómez Carrillo en esa compleja relación con el medio en el que son publicadas sus crónicas, pero también vemos al mismo tiempo una importante tendencia a separarse de un estilo estrictamente periodístico-informativo. Ahora bien, a través de las primeras crónicas de guerra podemos, de la misma manera, identificar una necesidad de diferenciación del estilo del reportero anglosajón y particularmente del de corresponsal de guerra, es decir, el autor busca una voz narrativa distinta, a pesar de formar parte de unos objetivos institucionales de información del Gobierno francés y de ser presentado por la prensa española como un corresponsal en el campo de batalla encargado de llevar la luz sobre la verdad de los hechos.

Gómez Carrillo no se interesa por la configuración política del contexto narrado o las estrategias militares de los grandes dirigentes para explicar el desarrollo y las consecuencias de los enfrentamientos, sino que se dedica a la observación

10 Véase Norton Cru, J., 1929.

11 Es el caso de Reflejos de la tragedia (1915), En el corazón de la tragedia (1916), En las trincheras (1916), El quinto libro de las crónicas (1922). 
del entorno a manera de un periplo o una aventura hacia el horror. Así entonces, es precisamente a partir de las estrategias narrativas de los relatos de viaje - los cuales habían ya popularizado al autor - que Gómez Carrillo pretende construir el discurso de sus crónicas de guerra, alejándose de todo matiz técnico-informativo o de todo carácter urgente de la información. Este último aspecto resulta trascendental cuando nos acercamos a la crónica del periodista sueco del mismo grupo, quien afirma que: "En attendant ils nous disent: vous pouvez faire de l'histoire militaire inédite, encore aujourd'hui, après deux mois, le grand public ne connaît pas exactement ce qui s'est passé, par exemple du 5 au 10 septembre" (Sjoestdt, p. 5). Es evidente que se abre a los visitantes la posibilidad de escribir la historia inmediata mediante el instrumento de la prensa de sus propios países, para lo cual es indispensable desarrollar una visión global del conflicto y de los actores que en él participan.

Por su parte, Gómez Carrillo (1922) prefiere distanciarse de las posibilidades de hacer periodismo de guerra para dar una visión más íntima en la que es posible dirigir la perspectiva de la narración hacia aspectos contextuales, sean estos históricos, artísticos o naturales. El ojo del observador logra así distanciarse del ruido de los cañones y de las estrategias de ataque para dar paso a la palabra del testigo directo y a las tradiciones rurales. De esta manera, después de haber llegado a la ciudad de Nancy con el grupo de periodistas, explica:

[...] mis señores compañeros toman muy en serio su carácter de corresponsales de guerra, que en cuanto pierden la huella de los ejércitos parecen extraviados y desorientados. En caravana han ido esta mañana a escribir algunas notas sobre los efectos sin gran importancia del bombardeo del mes de septiembre, y si han consentido en admirar algo, son las vidrieras de la iglesia de San Epvre que las bombas de un "Zeppelín" acababan de destruir. Luego, sin volver siquiera los ojos hacia el Palacio Ducal que alza en la vecindad su pórtico cincelado cual una joya, hanse vuelto al hotel en que el Gobierno nos aloja, para seguir estudiando en las cartas a gran escala las maniobras de las tropas que hace cuatro meses ganaron en las inmediaciones de la célebre batalla del Grand Couronné. (p.197)

En la cita anterior podemos ver claramente la diferencia en los objetivos de los corresponsales presentes en el grupo, quienes "toman muy en serio" su papel informativo. Además, lo que sorprende al cronista guatemalteco es la falta de interés por la observación y admiración del entorno en el que se encuentran, en particular en lo que concierne a los importantes monumentos que dan testimonio de un pasado glorioso y de una historia milenaria. El corresponsal de guerra se sitúa entonces en un espacio temporal inmediato en el cual es indispensable absorber la información de los eventos ocurridos, comprender y sintetizar la complejidad del presente para dar la información requerida por la prensa de sus países. Gómez 
Carrillo (1922) no puede concebir esta manera de analizar el entorno en el que se encuentra, y dice:

Yo por mi parte no entiendo ni de cartas ni de estrategia, los dejo irse sin tristeza, y muy solo, muy contento y muy curioso de cosas viejas me quedo en el antiguo barrio tranquilo. ¿Qué me importa, después de todo, una batalla que ya no forma parte de la actualidad que todavía no pertenece a la historia? (p. 198)

¿Cuáles son entonces las características principales que organizan las crónicas de guerra de Gómez Carrillo, si desde un principio pretende separarse del ejercicio que se le ha solicitado para la prensa de información? A nuestro parecer, es necesario ir a buscar estos recursos estilísticos en la concepción del autor en torno al viaje como una forma de desplazamiento espacio-temporal. En este, las huellas del pasado surgen a la vista del viajero por medio de una observación minuciosa y gracias al análisis de una importante cantidad de referencias literarias y artísticas de la cultura en cuestión. Las pistas de este procedimiento fácilmente reconocible en los viajes a Oriente realizados por el autor, pueden encontrarse en el famoso ensayo La psicología del viaje ${ }^{12}$, en el cual se desarrolla una reflexión acerca de la experiencia íntima del viajero.

Una de las motivaciones esenciales del viajero modernista es el ansia de extrañamiento en los paisajes exóticos. De este modo, es necesario dejar por un periodo las comodidades de las grandes metrópolis para adentrarse en un contexto desconocido, hacia un intento de descubrimiento del otro que podrá, en cierta medida, aportar algo al alma sensible que emprende el viaje. Así entonces, el regreso implica siempre una renovación o una muerte del yo anterior que no había aun realizado esta experiencia; el resultado es caracterizado por el autor con la referencia al poema de Edmond Haraucourt Partir c'est mourir un peu ${ }^{13}$. La experiencia del viaje en Gómez Carrillo (1919) está así íntimamente vinculada con una transformación profunda del sujeto, la cual puede darse de acuerdo con una serie de condiciones o de prerrogativas por medio de las que se pueda llegar al conocimiento:

Cuando nos vamos hacia tierras lejanas y transoceánicas, una inconsciente angustia oprime nuestras almas. Sin quererlo, nos interrogamos en secreto sobre aquello que puede cambiar durante nuestra ausencia. ¿Qué encontraremos al volver, de todo lo que dejamos...? Y nosotros mismos, ¿volveremos tal cual nos vamos...? Un filósofo pesimista nos dice: «No; no volveréis así. No. El que se va no vuelve nunca. Quien vuelve es otro, otro que es casi el mismo, pero que

12 El ensayo fue publicado por primera vez en el libro Pequeñas cuestiones palpitantes (1910) bajo el título "La psicología del viajero". Las referencias en el presente artículo corresponden al texto aparecido en el tomo de obras completas: Gómez Carrillo, 1919.

13 Para profundizar en el análisis del ensayo de Gómez Carrillo respecto del concepto de viaje ver: Barrientos Tecún, D., 2012. 
no es el mismo.» Y esto, que parece una paradoja, no es sino la más melancólica de las verdades. (p. 13)

La interpretación subjetiva del artista que viaja es sintetizada por el autor bajo el concepto de "sensaciones", de modo que sus relatos fueron recopilados en diferentes ocasiones a partir de este concepto ${ }^{14}$, el cual se diferencia de todo tipo de relato que se esfuerza en dar simplemente detalles de orden cronológico y de lugares por visitar a manera de guía turística ${ }^{15}$. Así entonces, la forma de plasmar este tipo de sensaciones tiene que ver con una actitud ante el viaje y sobre todo con una capacidad de observación y de traslado hacia otras épocas. Cuando Gómez Carrillo describe su llegada a Tokio, por ejemplo, no duda en confrontar su entorno con su imaginario previo sobre el lugar, alimentado por toda una serie de lecturas y de referencias históricas. De esta forma, el viajero reflexiona a partir de su mirada, pero sobre todo, toma en cuenta su capacidad de trasladarse hacia otro espacio temporal nunca antes visitado pero que sobrevive en la memoria de dicha civilización. Vemos, entonces, un interés particular en las huellas dejadas por un pasado glorioso o por los monumentos que pudieron sobrevivir al paso del tiempo: el viajero, para Gómez Carrillo (1919), debe poner especial atención en todos estos elementos reveladores del alma artística de un pueblo y que dan, a la vez, testimonio de una historia, la cual debe ser de alguna forma recuperada por ese visitante pasajero:

Poco a poco, el alma de la ciudad va revelándose. De los monumentos surge la historia. Los fantasmas pueblan las ruinas. La vida palpita. Y así, casi sin sentirlo, llego a creer, al cabo de algún tiempo, que no soy un extranjero, ni casi un forastero, y que formo parte de la población en la cual me encuentro. (p.32)

Esta manera de dirigir la mirada hacia los detalles que en principio podrían parecer vanos y que luego se reúnen con las observaciones sobre los monumentos importantes en una recuperación de las huellas de la historia, la podemos ver de forma patente en las descripciones de los pueblos arrasados por los alemanes. El cronista rehúye una vez más las descripciones estratégicas para tratar de retratar un alma del espacio visitado:

Nuestro capitán, siempre obsesionado por ideas de estrategia, no hace notar con cuánta ciencia Louvois escogió el sitio para poder dominar las rutas militares desde la alta terraza en que nos hallamos. Por mi parte, yo prefiero contemplar los muros agrietados, no por las bombas sino por el tiempo, y las torres, que

14 Sensaciones de París y de Madrid (1900), Sensaciones de Rusia (1905), De Marsella a Tokio. Sensaciones de Egipto (1906).

15 Gómez Carrillo los llama "detalles baedekerianos" como referencia a las conocidas guías de Karl Baedeker (1801-1859). 
se alzan, cubiertas de musgo, pregonando aún la gracia robusta de los grandes siglos de Francia. (Gómez Carrillo, 1922, pp. 27-28)

Ahora bien, si volvemos al contexto particular de 1914, más allá de la narración de los viajes en Oriente y de la trepidante vida parisina, encontramos a un corresponsal de guerra que se rehúsa a narrar el horror simplemente para cumplir con los requerimientos de la prensa. En esta nueva experiencia se reproducen las estrategias narrativas de las "sensaciones" del viaje para tratar un extrañamiento que se desarrolla en el centro mismo de Europa, cerca de la metrópolis, como una forma de "sensación de la guerra". Esta vez no es necesario dejar el continente para encontrar el extrañamiento, ya que la otredad se sitúa en el territorio propio. Además, este territorio se presenta como un espacio transformado, a través del cual es posible comprender la barbarie que allí se desarrolla. Campos de batalla (1922) se organiza primeramente a partir de la ubicación de una suerte de exotismo interior que rompe con el imaginario de Europa como centro de la civilización, el cual debe a su vez desmitificar toda idea gloriosa de la guerra. En la dedicatoria del libro, el autor manifiesta su propósito de desmitificar una idea romántica del combate bélico gracias a las imágenes estremecedoras de la guerra moderna: "¡Ved lo que es la guerra!... Ved que no hay en ella armaduras lucientes, ni clarines sonoros, ni bellos gestos heroicos, ni nobles generosidades, ni estandartes vistosos, sino sangre, miseria, llamas, crímenes, sollozos..." (Gómez Carrillo, 1922, p.6).

La primera de las crónicas de guerra recogida en el libro, De París a Esternay, reproduce igualmente la estrategia discursiva del relato de viaje, ya bien dominada por Gómez Carrillo. A diferencia de sus colegas suizo y noruego, esta primera crónica no retoma datos prácticos o técnicos de los motivos y condiciones del desplazamiento. Observamos entonces que no hay un afán de comprensión del contexto político que pueda dar pistas más claras a los lectores sobre los acontecimientos narrados por un testigo que se dirige al frente de batalla. Gómez Carrillo (1922) lleva a su lector dentro de un viaje en el cual se mezclan diferentes temporalidades gracias al paisaje desolado y a las ruinas de la campiña francesa. De esta forma, el espacio que recorre el viajero permite el inicio de múltiples digresiones, a manera de viajes interiores que muestran no solo la importante cantidad de referencias históricas y artísticas del viajero, sino también la oportunidad de realizar una lectura diacrónica del espacio visitado. Más adelante, la posibilidad de una invasión de París por las tropas alemanas en septiembre de 1914, da pie al cronista para revisitar otras amenazas sufridas por la capital:

Por fortuna, Santa Genoveva estaba ahí, en su terraza milenaria, tal cual la vemos en los frescos de Puvis de Chavannes, para renovar el milagro que asombró a los contemporáneos de Atila. Los bárbaros de hoy, como los de hace siglos y 
siglos, huyeron de las inmediaciones de Lutecia sin haber siquiera logrado ver las torres de sus iglesias. (p.16)

Unos días después, al acercarse a la ciudad de Senlis, es esta misma oposición entre tiempos pasados cargados de nostalgia la que organiza la estructura de la crónica, reforzando así el impacto sufrido por el viajero al constatar la degradación y las huellas de la guerra en un espacio antes conocido. Es precisamente a partir de este tipo de tópico narrativo que el autor logra reproducir el extrañamiento buscado en el relato de viajes al constatar la devastación ocasionada por la guerra. Así entonces, los recuerdos se unen a las referencias históricas para reforzar la "sensación" del viaje:

Un día ha bastado para que la población que los siglos habían patinado con matices de eternidad se convierta en campos de ruinas. [...] Nada, empero, menos trágico de aspecto que estos sitios, en los cuales las imágenes más elegantes se unen a los más exquisitos recuerdos históricos. (Gómez Carrillo, 1922, pp.43-44).

De esta misma manera, las diferentes regiones visitadas en el viaje hacia las provincias del este del país, dan pie al autor para retomar los episodios más gloriosos de las guerras pasadas. Los ejemplos se repiten de forma continua a lo largo de todas las crónicas, en donde vemos una importante distancia entre la experiencia de la guerra vivida a través de los relatos épicos de la literatura y de las imágenes de los pintores románticos, con la experiencia vivida a partir de 1914, en donde la guerra deja de parecer heroica.

Esta misma diferenciación salta a la vista de forma continua por medio de la evocación de una imagen idílica de la Francia eterna que se puede aún encontrar en los pueblos que están siendo marcados por el peso de la guerra. El recorrido del grupo de periodistas por los campos de Meaux permite a Gómez Carrillo (1922) la representación de estampas costumbristas, las cuales se oponen directamente a la imagen central y cosmopolita de París. En este caso, una vez más, se logra realizar uno de los caracteres determinantes del viaje modernista al poner de relieve la vida y costumbres de los pueblos, eje central de una identidad que debe ser defendida frente a la amenaza teutona:

Sentaos a la puerta de un café un día cualquiera, y os creéis ante una estampa de otro tiempo. Los burgueses marchan sin prisa hacia los campos de las ferias locales, mientras las burguesas se encaminan, al son de las campanas, hacia las iglesias. [...] El ferrocarril que pasa por su gare no se detiene sino para llevarse sacos de trigo. En cuanto a los habitantes en general, prefieren seguir sirviéndose de sus tradicionales cochecillos, algo desvencijados, para ir a Château-Thierry, a Lagny, a Coulommiers. En cuanto a París, c'est un voyage, como me 
decía hace un instante un molinero, que no ha vuelto a la capital después de la Exposición. (pp.35-36)

Esta última referencia a París hecha por un habitante del pueblo marca bien la diferencia entre ambos mundos, reafirmando así el sentido del viaje y el extrañamiento nostálgico que produce el hecho de adentrarse en el campo. De la misma manera que las evocaciones históricas dan una nueva dimensión a la visita del cronista, las descripciones de un espacio campestre idílico proporcionan un contraste determinante en el contexto de la guerra. Campos de batalla (1922) lleva al lector hacia un reconocimiento de los efectos devastadores de la guerra por medio de un recorrido que se dirige hacia las trincheras, es decir, hacia el frente en donde se encuentra la acción principal. En esta estrategia los paisajes idílicos se transforman poco a poco en espacios destruidos y en poblaciones masacradas, mostrando así el carácter sin sentido de la guerra, en particular cuando esta toca las producciones máximas de la cultura tales como los monumentos, las catedrales, las plazas y sus esculturas, entre otros.

Esto nos lleva a la última de las estrategias más utilizadas por Gómez Carrillo en su primer tomo de crónicas bélicas: la búsqueda de los testigos oculares. Como vimos al inicio, el cronista se sitúa en una posición privilegiada en cuanto a la cercanía con los hechos narrados, condición necesaria para presentar un ejercicio de corresponsal, es decir, que el cronista es ante todo testigo de los eventos. Sin embargo, las condiciones en las que se da el recorrido por los campos de ruina hacen necesaria la palabra de quienes vivieron los primeros bombardeos de inicios del mes de septiembre de 1914. Podemos ver que la crónica da en cierta medida la palabra a otras voces capaces de narrar el horror vivido. Estos testimonios son posteriormente reelaborados dentro del estilo particular del autor:

Todo el pueblo ha venido a agruparse a nuestro derredor, lleno de curiosidad. Todos nos dirigen la palabra. Todos desean saber lo que hemos venido a buscar. Todos contemplan con cariño y sin respeto el uniforme claro del capitán que nos guía. A la menor pregunta que dirigimos a uno, diez o doce dispútanse el placer de contestarnos. La población entera muéstrase impaciente de contarnos sus impresiones de la tragedia. Los niños mismos, escapándose por las puertecillas de las tiendas, acuden, risueños a enterarse de lo que hacemos y de lo que vemos. (Gómez Carrillo, 1922, p.30)

Como se ve en la cita anterior, el autor privilegia la palabra de los habitantes de los lugares visitados para dar una dimensión en apariencia más confiable de los acontecimientos. Así, asistimos a la reelaboración de los hechos por medio de la palabra de los testigos, quienes narran las vejaciones sufridas por la población, las injusticias y los bombardeos. La estrategia principal desarrollada por el cronista 
para cumplir, en cierta forma, con el contrato de reportero en zona de guerra, es la de escuchar a las víctimas del conflicto. En este sentido, la subjetividad del narrador no se presenta como la fuente principal del relato a la manera de un sujeto testimoniante quien asegura, como lo explica Ricœur (1922): "yo estuve allí" (p.204)y, por ende, lo que cuento es cierto, sino que su sensibilidad pretende dar cuenta sobre todo del desastre cultural. Más delante, es el mismo Gómez Carrillo quien se encuentra frente a la muerte y la destrucción en mayor escala, para dar así su propio testimonio y sus "sensaciones de la guerra", pero estas no se pretenden palabras de testigo-víctima propiamente dicho. Una vez más, la observación de las ruinas y los estragos provoca inevitablemente una reflexión sobre la capacidad humana para destruir todo lo bello que esta misma ha creado.

\section{Conclusión}

A lo largo de las crónicas del primer tomo, podemos constatar el avance hacia el horror en el campo de batalla, no solamente siguiendo el recorrido cartográfico del autor, sino también analizando su mirada y su reflexión sobre la guerra como fenómeno. Para Gómez Carrillo, desde el inicio del recorrido, el concepto de guerra está íntimamente relacionado con los momentos más gloriosos de las batallas narrados por la literatura y la pintura, de forma que podemos ver una importante dificultad para comprender los detalles de la guerra moderna a la que se ve enfrentado, sus estrategias y su organización. El hecho de constatar los efectos del conflicto, el horror infligido a la población y sobre todo la destrucción de obras mayores de la civilización, provoca un choque determinante en la visión de la guerra. Es precisamente la impresión causada en artistas e intelectuales de la época al ver los destrozos en la Catedral de Reims, por ejemplo, a lo que dice Gómez Carrillo (1922): “¿Qué idea se harán las generaciones futuras de un siglo que proclama con orgullo su cultura y que incendia lo mejor que el genio humano ha creado?" (p.83). El contraste extremo entre la guerra vista de lejos y la guerra vista de cerca es la característica principal que se destaca en las crónicas de Campos de batalla (1922), a manera de una suerte de viaje hacia el horror:

¡Ah! ¡Cuán diferente es la guerra vista de lejos, con sus grandezas, con su estrépito, con su belleza teatral, con sus magníficos toques de clarines, y la guerra vista de cerca, con sus miserias, con sus atrocidades, con sus llamas, con sus gestos dolorosos, con sus muertos que se pudren en las trincheras abandonadas! (p.68)

Como hemos podido observar por medio de los aspectos más relevantes de la estructura narrativa de las crónicas, Gómez Carrillo presenta un ejercicio de crónica bélica bastante particular, más allá de la hibridación propia a la crónica modernista. Así entonces, el lector se enfrenta a un verdadero relato de viaje que retoma los caracteres esenciales de la escritura de Gómez Carrillo, transponiendo la idea 
de sensaciones tan presente en su obra precedente, para narrar un viaje interno hacia el descubrimiento de la guerra moderna. El hecho de no lograr identificarse con un corresponsal, subraya aún más esta cualidad de la observación desde la perspectiva del viajero que se adentra en un mundo desconocido. El viaje que el cronista encargado de informar al mundo hispanohablante inicia en 1914, da cuenta bastante temprano del sin sentido de la guerra europea, del desastre humano, artístico y cultural que implica, todo esto sin entrar completamente en el juego dicotómico de denigración del enemigo, sino deplorando constantemente el porvenir después del desastre.

\section{Referencias}

Barrientos Tecún, D. (2012). "Estética del viaje y de lo efímero en Enrique Gómez Carrillo". En II Congreso Internacional Rencuentro con Enrique Gómez Carrillo. Guatemala: Universidad Rafael Landívar, en línea: http:// biblio3.url.edu.gt/Gomez/Ponencias.php

Gómez Carrillo, E. (1922). Campos de batalla y campos de ruina [1915], Tomo XVII de las Obras Completas. Madrid: Mundo Latino.

. (1919). El primer libro de las crónicas, Tomo VI de las Obras Completas. Madrid: Mundo Latino.

.(1923). Jerusalény Tierra Santa [1912]. Madrid: Editorial Renacimiento.

. (1915a). Parmi les ruines, de la Marne au Grand Couronné. Nancy-Paris : Librairie militaire Berger-Levrault, trad. J. N. Champeaux.

. (1915b). Among the ruins. London: William Heinemann, trad. Florence Simmonds.

González, A. (1983). La crónica modernista hispanoamericana. Madrid: José Porrúa Turanzas.

Norton Cru, J. (1993). Témoins : essai d'analyse et de critique des souvenirs de combattants édités en français de 1915 à 1928 [1929]. Paris: Les Étincelles, Reed. Presses universitaires de Nancy.

Ricœur P. (2000). La mémoire, l'histoire, l'oubli. Paris: Seuil.

Siskind, M. (2016). "La Primera Guerra Mundial como evento latinoamericano: modernismo, visualidad y distancia cosmopolita". En Cuadernos de literatura, vol. xx, $\mathrm{N}^{\circ} 39$, enero-junio, p. 230-251.

Sjoestedt, E. (1915). Impressions d'un neutre. Lettres du théâtre des opérations, [traducido del sueco]. Paris: Édition de l'Agence Paris-Baltique. 
Wagnière, G. (1915). Près de la guerre : en Suisse, en France, en Angleterre, sur le front. Genève: André Julien éditeur.

Wieviorka, A. (1998). L'ère du témoin. Paris: Plon.

\section{Artículo de prensa:}

Diario El Liberal, “Gómez Carrillo a la guerra”. Madrid: 10 de noviembre de 1914. 